\title{
Article \\ Characteristics and Risk Factors for Intensive Care Unit Cardiac Arrest in Critically Ill Patients with COVID-19-A Retrospective Study
}

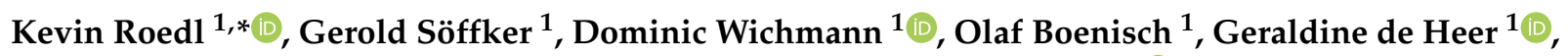 \\ Christoph Burdelski $^{1}$, Daniel Frings ${ }^{1}$, Barbara Sensen ${ }^{1}$, Axel Nierhaus ${ }^{1} \mathbb{D}$, Dirk Westermann ${ }^{2}$, Stefan Kluge ${ }^{1}$ \\ and Dominik Jarczak ${ }^{1}$ (D) \\ 1 Department of Intensive Care Medicine, University Medical Centre Hamburg-Eppendorf, \\ 20246 Hamburg, Germany; g.soeffker@uke.de (G.S.); d.wichmann@uke.de (D.W.); o.boenisch@uke.de (O.B.); \\ deheer@uke.de (G.d.H.); c.burdelski@uke.de (C.B.); d.frings@uke.de (D.F.); b.sensen@uke.de (B.S.); \\ nierhaus@uke.de (A.N.); s.kluge@uke.de (S.K.); d.jarczak@uke.de (D.J.) \\ 2 Department of Interventional and General Cardiology, University Heart Centre Hamburg, \\ 20246 Hamburg, Germany; d.westermann@uke.de \\ * Correspondence: k.roedl@uke.de; Tel.: +49-40-7410-57020
}

Citation: Roedl, K.; Söffker, G.; Wichmann, D.; Boenisch, O.; de Heer, G.; Burdelski, C.; Frings, D.; Sensen, B.; Nierhaus, A.; Westermann, D.; et al. Characteristics and Risk Factors for Intensive Care Unit Cardiac Arrest in Critically Ill Patients with COVID-19-A Retrospective Study. J. Clin. Med. 2021, 10, 2195. https:// doi.org/10.3390/jcm10102195

Academic Editors: Lukasz Szarpaka and Roland Bingisser

Received: 24 April 2021

Accepted: 17 May 2021

Published: 19 May 2021

Publisher's Note: MDPI stays neutral with regard to jurisdictional claims in published maps and institutional affiliations.

Copyright: (C) 2021 by the authors Licensee MDPI, Basel, Switzerland. This article is an open access article distributed under the terms and conditions of the Creative Commons Attribution (CC BY) license (https:// creativecommons.org/licenses/by/ $4.0 /)$.
Abstract: The severe acute respiratory syndrome coronavirus-2 (SARS-CoV-2) causing the coronavirus disease 2019 (COVID-19) led to an ongoing pandemic with a surge of critically ill patients. Very little is known about the occurrence and characteristic of cardiac arrest in critically ill patients with COVID-19 treated at the intensive care unit (ICU). The aim was to investigate the incidence and outcome of intensive care unit cardiac arrest (ICU-CA) in critically ill patients with COVID-19. This was a retrospective analysis of prospectively recorded data of all consecutive adult patients with COVID-19 admitted (27 February 2020-14 January 2021) at the University Medical Centre Hamburg-Eppendorf (Germany). Of 183 critically ill patients with COVID-19, 18\% $(n=33)$ had ICU-CA. The median age of the study population was $63(55-73)$ years and $66 \%(n=120)$ were male. Demographic characteristics and comorbidities did not differ significantly between patients with and without ICU-CA. Simplified Acute Physiological Score II (SAPS II) (ICU-CA: median 44 points vs. no ICU-CA: 39 points) and Sequential Organ Failure Assessment (SOFA) score (median 12 points vs. 7 points) on admission were significantly higher in patients with ICU-CA. Acute respiratory distress syndrome (ARDS) was present in $91 \%(n=30)$ with and in $63 \%(n=94)$ without ICU-CA $(p=0.002)$. Mechanical ventilation was more common in patients with ICU-CA ( $97 \%$ vs. $67 \%)$. The median stay in ICU before CA was $6(1-17)$ days. A total of 33\% $(n=11)$ of ICU-CAs occurred during the first $24 \mathrm{~h}$ of ICU stay. The initial rhythm was non-shockable (pulseless electrical activity (PEA)/asystole) in $91 \%(n=30) ; 94 \%(n=31)$ had sustained return of spontaneous circulation (ROSC). The median time to ROSC was 3 (1-5) minutes. Patients with ICU-CA had significantly higher ICU mortality (61\% vs. 37\%). Multivariable logistic regression showed that the presence of ARDS (odds ratio (OR) $4.268,95 \%$ confidence interval (CI) 1.211-15.036; $p=0.024$ ) and high SAPS II (OR 1.031, 95\% CI $0.997-1.065 ; p=0.077$ ) were independently associated with the occurrence of ICU-CA. A total of $18 \%$ of critically ill patients with COVID-19 suffered from a cardiac arrest within the intensive care unit. The occurrence of ICU-CA was associated with presence of ARDS and severity of illness.

Keywords: COVID-19; coronavirus disease; multiple organ failure; intensive care unit; SARS-CoV-2; cardiac arrest; cardiopulmonary resuscitation; in-hospital cardiac arrest; ICU-CA

\section{Introduction}

The severe acute respiratory syndrome coronavirus 2 (SARS-CoV-2) emerged in 2019 in China and caused a worldwide pandemic [1,2]. Although the majority of patients have an asymptomatic or mild course of disease, about $5 \%$ suffer from severe illness complicated 
by acute respiratory distress syndrome (ARDS) or other end-organ failure [3]. During the pandemic, an increase in out-of-hospital cardiac arrest (OHCA) cases was observed in different regions [4,5]. Relatively little is known about the occurrence of in-hospital cardiac arrest (IHCA) during the coronavirus disease 2019 (COVID-19) pandemic [6,7]. One study reported a shift of cardiac arrest (CA) characteristics during the pandemic [6]. However, different studies reported on characteristics of IHCA in patients with COVID-19 [8-11]. In most studies, a devastating mortality ranging from $88-100 \%$ has been reported $[8,10-12]$. A recent multicenter study from the US showed large variations in outcome after IHCA between centers [13]. A large number of IHCA in the recent literature occurred within the intensive care unit (ICU) $[8,12,13]$. Cardiac arrest in the ICU, also known as ICU-CA, represents a less investigated subgroup of IHCA. Due to clinically important differences, ICU-CA should be considered separately from IHCA in a general ward [14]. The incidence of ICU-CA varies greatly in the literature (4-78/1000 admissions) [14,15]. Survival rates to discharge after ICU-CA are diverse and range from 2 to $79 \%$, mainly depending on the ICU population studied $[14,15]$. However, one recent study in critically ill patients with COVID-19 reported a mortality rate of $88 \%$ [11]. Mortality after CA is mainly triggered by post-CA shock and brain injury [16]. Further, it has been shown that organ failure before and after ICU-CA is common and the severity of illness after ICU-CA and the occurrence of liver failure are independent predictors of mortality [17]. To date, most studies focused on the characteristics of IHCA without comparing clincical characteristics to other patients with COVID-19. Further, studies focusing on critically ill patients and risk factors for ICU-CA are scarce.

However, data on ICU-CA within critically ill patients with COVID-19 are limited. In the present study, we aimed to investigate the occurrence, risk factors and outcome of patients with COVID-19 suffering from ICU-CA. Further, we investigated factors associated with favorable outcome within ICU-CA.

\section{Materials and Methods}

\subsection{Study Population, Design and Ethics}

This was a retrospective analysis of data prospectively recorded at the University Medical Centre Hamburg-Eppendorf (Germany). All consecutive adult patients with COVID-19 admitted (27 February 2020-14 January 2021) to the Department of Intensive Care Medicine were included. The study complied with the Declaration of Helsinki. The Ethics Committee of the Hamburg Chamber of Physicians was informed about the study (No.: WF-60/21). The requirement for informed patient consent was waived due to the use of only anonymized data collected during routine clinical care. The last day of follow-up was 15 March 2021.

\subsection{Inclusion and Exclusion Criteria}

We included all consecutive critically ill adult patients ( $\geq 18$ years) with confirmed COVID-19 who were admitted to the Department of Intensive Care Medicine during the study period. Patients $<18$ years or with a prior event of OHCA/IHCA event before ICU admission, as well as cardiac re-arrest after ICU admission, were not considered as ICU-CA and were therefore excluded. Patients without confirmed COVID-19 were excluded.

\subsection{Study Definitions and Patient Management}

Cardiac arrest was defined as cessation of circulation, and therefore, an indication for chest compression and/or cardiac defibrillation in patients who had a pulse and circulation at the time of ICU admission. The sustained return of spontaneous circulation (ROSC) was defined as stable circulation for at least $20 \mathrm{~min}$. The assessment of neurological outcome was performed within routine clinical practice using cerebral performance categories (CPCs) after ICU-CA and during follow-up. A CPC score of 1-2 was defined as a favorable neurological outcome, and a score of $3-5$ was defined as an unfavorable neurological outcome. Survival was assessed through the end of the ICU stay. Cardiopulmonary resus- 
citation and post-CA care were performed in accordance with the European Resuscitation Council guidelines [18,19]. Data were collected according to Utstein-style guidelines [20]. Hypoxic liver injury (HLI) was diagnosed according to established criteria [21]. Confirmed COVID-19 was defined as a positive result on a reverse transcriptase-polymerase chain reaction, and only laboratory-confirmed cases were counted as COVID-19. ARDS was defined using the $\mathrm{PaO}_{2} / \mathrm{FiO}_{2}$ ratio (Horowitz index) according to the Berlin definition [22,23]. The severity of illness was evaluated by the sequential organ failure assessment (SOFA) score [24] and simplified acute physiology (SAPS II) [25] score. The Charlson comorbidity index (CCI) [26] was calculated in all patients.

\subsection{Data Collection}

Data were collected through electronic patient data management systems (PDMS, Integrated Care Manager ${ }^{\circledR}$ (ICM), Version 9.1-Draeger Medical, Luebeck, Germany; Soarian Clinicals, Version 4.3.200-Cerner Health Service, Inc. (North Kansas City, MO, USA) and consisted of age, sex, comorbidities, admission diagnosis, length of ICU stay, treatment modalities, organ support (mechanical ventilation, vasopressor, renal replacement therapy (RRT), blood transfusions, antibiotics, antivirals, etc.), laboratory parameters and further clinical parameters of interest through the end of ICU stay. Pre-existing medication was recorded based on known regular medications and medications on admission. Laboratory assessment was performed daily as part of the clinical routine.

\subsection{Statistical Analysis}

The results are presented as counts and relative frequencies or medians and $25-75 \%$ interquartile ranges (IQRs). Binary variables were compared via chi-square analysis/Fisher's exact test, as appropriate. Metric variables were compared via the Mann-Whitney U test. We used multivariable logistic regression to investigate risk factors associated with occurrence of ICU-CA. Factors of clinical relevance were selected and included. A stepwise backward elimination approach that gradually reduces the initial model was used; variables that caused a change in estimates $>10 \%$ / statistically significant remained in the model. Statistical analysis was conducted using IBM SPSS Statistics Version 24.0 (IBM Corp., Armonk, NY, USA). The study was prepared in accordance with the STROBE (STrengthening the Reporting of OBservational studies in Epidemiology) recommendations.

\section{Results}

\subsection{Study Population}

During the study period (1 March 2020 to 14 January 2021), a total of 194 patients with confirmed COVID-19 were treated at the Department of Intensive Care Medicine at the University Medical Centre Hamburg-Eppendorf. After the exclusion of cases who were admitted more than one time in the aforementioned time frame, we could include 183 patients in the final cohort. Within the cohort, we could identify $33(18 \%)$ patients who had suffered from an ICU-CA and $150(82 \%)$ patients who did not suffer from an ICU-CA (see study flow chart, Figure 1).

\subsection{Baseline and ICU Characteristics of the Study Populations}

Detailed baseline characteristics are shown in Table 1 . The median age of the study population was $63(55-73)$ years and $66 \%(n=120)$ were male. Comorbidities, displayed by CCI, were a median of $2(1-3)$ points. Leading comorbidities were arterial hypertension $(57 \%, n=105)$, diabetes mellitus $(33 \%, n=60)$, malignant condition (tumor or hematologic malignancy) $(25 \%, n=45)$, coronary heart disease $(19 \%, n=34)$, chronic kidney disease $(15 \%, n=28)$ and chronic respiratory disease $(15 \%, n=27)$. Demographic characteristics and comorbidities did not differ significantly between both groups (see Table 1 and Supplementary Table S1). The time from the first positive test for COVID-19 to ICU admission was a median of 5 (1-12) days and differed between both groups (ICU-CA: 8 days vs. no 
ICU-CA: 5 days; $p=0.032$ ). Presenting COVID-19 symptoms did not differ significantly between both groups.

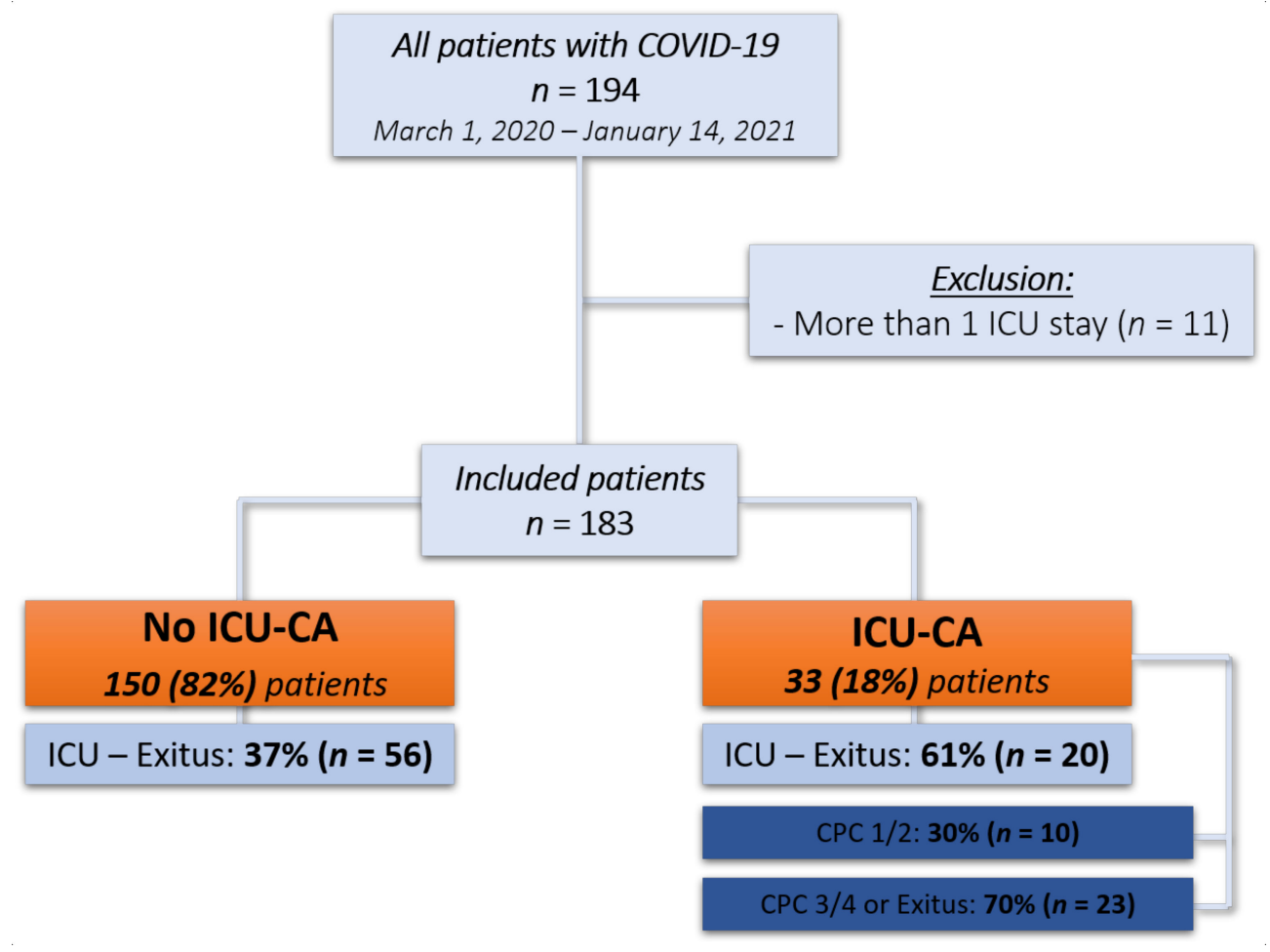

Figure 1. Study flow chart.

Table 1. Baseline and ICU-characteristics of patients stratified according to ICU cardiac arrest (ICU-CA) and no ICU cardiac arrest (no ICU-CA).

\begin{tabular}{|c|c|c|c|c|}
\hline \multirow{2}{*}{ Parameters } & All Patients & $I C U-C A$ & No ICU-CA & \multirow{2}{*}{$p$-Value } \\
\hline & $(n=183)$ & $(n=33)$ & $(n=150)$ & \\
\hline \multicolumn{5}{|l|}{ Demographics } \\
\hline Age, years median (IQR) & $63(55-73)$ & $64(55-75)$ & $62(55-73)$ & 0.627 \\
\hline Gender, male $n(\%)$ & $120(66)$ & $20(61)$ & $100(67)$ & 0.507 \\
\hline Height, cm median (IQR) & $175(168-180)$ & $172(166-180)$ & $175(169-180)$ & 0.238 \\
\hline Weight, kg median (IQR) & $85(73-100)$ & $85(72-100)$ & $84(73-100)$ & 0.947 \\
\hline BMI, $\mathrm{kg} / \mathrm{m}^{2}$ median (IQR) & $27(24-32)$ & $29(24-33)$ & $27(24-32)$ & 0.398 \\
\hline \multicolumn{5}{|l|}{ Comorbidities } \\
\hline Charlson comorbidity index, pts.; median (IQR) & $2(1-3)$ & $2(1-3)$ & $2(1-3)$ & 0.801 \\
\hline Arterial hypertension, $n(\%)$ & $105(57)$ & $22(67)$ & $83(55)$ & 0.233 \\
\hline Coronary heart disease, $n(\%)$ & $34(19)$ & $7(21)$ & $27(18)$ & 0.534 \\
\hline Chronic kidney disease, $n(\%)$ & $28(15)$ & $3(9)$ & $25(17)$ & 0.274 \\
\hline Chronic respiratory disease, $n(\%)$ & $27(15)$ & $5(15)$ & $22(15)$ & 0.943 \\
\hline Diabetes, $n(\%)$ & $60(33)$ & $12(36)$ & $48(32)$ & 0.259 \\
\hline Malignant condition, $n(\%)$ & $45(25)$ & $9(27)$ & $36(24)$ & 0.693 \\
\hline \multicolumn{5}{|l|}{ COVID-19 } \\
\hline Positive test to ICU, days median (IQR) & $5(1-12)$ & $8(3-17)$ & $5(1-11)$ & 0.032 \\
\hline Cough, $n(\%)$ & $82(44)$ & $16(48)$ & $66(44)$ & 0.613 \\
\hline Shortness of breath, $n(\%)$ & $111(61)$ & $19(58)$ & $92(61)$ & 0.689 \\
\hline Fever, $n(\%)$ & $81(44)$ & $13(39)$ & $68(45)$ & 0.534 \\
\hline Fatigue, $n(\%)$ & $24(13)$ & $4(12)$ & $20(13)$ & 0.852 \\
\hline Myalgia, $n(\%)$ & $9(5)$ & $2(6)$ & $7(5)$ & 0.737 \\
\hline
\end{tabular}


Table 1. Cont.

\begin{tabular}{|c|c|c|c|c|}
\hline \multirow{2}{*}{ Parameters } & \multirow{2}{*}{$\begin{array}{c}\text { All Patients } \\
(n=183)\end{array}$} & \multirow{2}{*}{$\begin{array}{c}I C U-C A \\
(n=33)\end{array}$} & \multirow{2}{*}{$\begin{array}{c}\text { No ICU-CA } \\
(n=150)\end{array}$} & \multirow{2}{*}{$p$-Value } \\
\hline & & & & \\
\hline \multicolumn{5}{|l|}{ Disease Severity on admission } \\
\hline SAPS II (pts.) median (IQR) & $40(33-48)$ & $44(37-52)$ & $39(32-45)$ & 0.016 \\
\hline SOFA (pts.) median (IQR) & $7(3-12)$ & $12(6-13)$ & $7(3-11)$ & 0.004 \\
\hline \multicolumn{5}{|l|}{ ICU Procedures } \\
\hline Mechanical ventilation, $n(\%)$ & $133(73)$ & $32(97)$ & $101(67)$ & 0.001 \\
\hline HFNC, $n(\%)$ & $67(37)$ & $8(24)$ & $59(39)$ & 0.103 \\
\hline $\mathrm{NIV}, n(\%)$ & $49(27)$ & $9(27)$ & $40(27)$ & 0.943 \\
\hline $\mathrm{ECMO}, n(\%)$ & $52(28)$ & $17(52)$ & $35(23)$ & 0.001 \\
\hline Vasopressor, $n(\%)$ & $145(79)$ & $32(97)$ & $113(75)$ & 0.006 \\
\hline RRT, $n(\%)$ & $87(48)$ & $22(67)$ & $65(43)$ & 0.015 \\
\hline \multicolumn{5}{|l|}{ ARDS and Management } \\
\hline ARDS & $124(68)$ & $30(91)$ & $94(63)$ & 0.002 \\
\hline -Mild & $7(4)$ & $1(3)$ & $6(4)$ & 0.314 \\
\hline -Moderate & $24(13)$ & $2(6)$ & $22(15)$ & 0.037 \\
\hline -Severe & $93(51)$ & $27(82)$ & $66(44)$ & 0.049 \\
\hline Inhaled vasodilator & $57(31)$ & $15(45)$ & $42(28)$ & 0.05 \\
\hline Prone positioning & $95(52)$ & $17(52)$ & $78(52)$ & 0.96 \\
\hline Neuromuscular blockade & $42(23)$ & $9(27)$ & $33(22)$ & 0.514 \\
\hline Steroid therapy & $118(64)$ & $23(70)$ & $95(63)$ & 0.489 \\
\hline \multicolumn{5}{|l|}{ Complications } \\
\hline Heart failure, $n(\%)$ & $8(4)$ & $2(6)$ & $6(4)$ & 0.6 \\
\hline Pulmonary embolism, $n(\%)$ & $13(7)$ & $2(6)$ & $11(7)$ & 0.797 \\
\hline Deep vein thrombosis, $n(\%)$ & $15(8)$ & $1(3)$ & $14(9)$ & 0.232 \\
\hline Myocardial infarction, $n(\%)$ & $7(4)$ & $3(9)$ & $4(3)$ & 0.082 \\
\hline Septic shock, $n(\%)$ & $80(44)$ & $20(61)$ & $60(40)$ & 0.035 \\
\hline \multicolumn{5}{|l|}{ Outcome } \\
\hline ICU mortality, $n(\%)$ & $76(42)$ & $20(61)$ & $56(37)$ & 0.014 \\
\hline In-hospital mortality, $n(\%)$ & $78(43)$ & $20(61)$ & $58(39)$ & 0.021 \\
\hline Length of stay-ICU, days median (IQR) & $13(5-25)$ & $21(8-32)$ & $12(5-24)$ & 0.159 \\
\hline
\end{tabular}

Abbreviations: cm, centimeter; BMI, body mass index; kg, kilogram; ICU, intensive care unit; IQR, interquartile range; $n$, number; pts, points; min, minute; MAP, mean arterial pressure; COVID-19, coronavirus disease 2019; HFNC, high flow nasal cannula; NIV, non-invasive ventilation; RRT, renal replacement therapy; ECMO, extracorporeal membrane oxygenation.

Disease severity displayed by SAPS II (median: 44 points vs. 39 points) and SOFA score (median: 12 points vs. 7 points) on admission was significantly higher in patients with ICUCA. Non-invasive ventilation (NIV) and high flow nasal cannula (HFNC) was comparably used in both groups. Mechanical ventilation was necessary in $73 \%(n=133)$ of the whole cohort and was significantly more common in patients with ICU-CA $(97 \%$ vs. $67 \%)$. ARDS was present in 68\% $(n=124)$ of patients, in $91 \%(n=30)$ with and in $63 \%(n=94)$ without ICU-CA $(p=0.002)$. ARDS management included prone positioning $(n=95)$, neuromuscular blockade $(n=42)$, inhaled nitric oxide $(n=57)$ and glucocorticoid therapy $(n=118)$ within the whole cohort and were evenly balanced between both groups. Due to severe ARDS accompanied by life-threatening hypoxemia, veno-venous extracorporeal membrane oxygenation (ECMO) was established in $28 \%(n=52)$ and was significantly more common in patients with ICU-CA ( $52 \%$ vs. $23 \%)$. The use of renal replacement therapy (RRT) was frequent in both groups $(67 \%$ vs. $43 \%, p=0.015)$. Further, patients with ICU-CA had a median longer ICU stay, with 21 (8-32) compared to 12 (5-24) days.

\subsection{Characteristics of Intensive Care Unit Cardiac Arrest}

The characteristics of ICU-CA are shown in detail in Table 2 and Supplementary Table S2. Thirty-three $(18 \%)$ patients of the cohort suffered from cardiac arrest during the ICU stay. The median stay before ICU-CA was $6(1-17)$ days. A total of 33\% $(n=11)$ of ICU-CAs occurred during the first $24 \mathrm{~h}$ of ICU stay. The initial cardiac rhythm was non-shockable (PEA/asystole) in $91 \%(n=30)$. Defibrillation was performed in 15\% $(n=5)$ of the patients. 


\begin{abstract}
A total of $94 \%(n=31)$ had sustained ROSC, and $21 \%(n=7)$ suffered from cardiac re-arrest. The median time to ROSC was 3 (1-5) minutes. A mechanical compression device was used in one patient with prolonged CPR. The cause of cardiac arrest was presumed non-cardiac in $85 \%(n=28)$. Epinephrine was used during CA in $79 \%(n=26)$; the median epinephrine dose was $1(1-2) \mathrm{mg}$. Targeted temperature management was applied in $48 \%(n=16)$. The highest lactate was $4.6(3.1-8.3) \mathrm{mmol} / \mathrm{l}$ and the lowest $\mathrm{pH}$ was 7.2 (7.12-7.3), after ICU-CA, respectively.
\end{abstract}

Table 2. Cardiac arrest and ICU characteristics of patients with ICU-CA stratified according favorable and unfavorable outcome.

\begin{tabular}{|c|c|c|c|c|}
\hline \multirow{2}{*}{ Parameters } & All Patients & ICU-CA Favorable & ICU-CA Unfavorable & \multirow{2}{*}{ p-Value } \\
\hline & $(n=33)$ & $(n=10)$ & $(n=23)$ & \\
\hline \multicolumn{5}{|l|}{ Cardiac arrest Characteristics } \\
\hline Initial rhythm shockable (VT/VF), $n(\%)$ & $3(9)$ & $2(20)$ & $1(4)$ & 0.151 \\
\hline Defibrillation, $n(\%)$ & $5(15)$ & $1(10)$ & $4(17)$ & 0.586 \\
\hline Sustained ROSC, $n(\%)$ & $31(94)$ & $10(100)$ & $21(91)$ & 0.336 \\
\hline Cardiac re-arrest, $n(\%)$ & $7(21)$ & $0(0)$ & $7(30)$ & 0.049 \\
\hline Presumed non-cardiac cause, $n(\%)$ & $28(85)$ & $8(80)$ & $20(87)$ & 0.609 \\
\hline Epinephrine median (IQR) & $1(1-2)$ & $2(1-2)$ & $1(1-2.3)$ & 0.501 \\
\hline \multicolumn{5}{|l|}{ Ischemic time, min; median (IQR) } \\
\hline -No-flow & $0(0-0)$ & $0(0-0)$ & $0(0-0)$ & 0.363 \\
\hline -Total resuscitation time & $3(1-5)$ & $2(0.8-4.5)$ & $4(1-6)$ & 0.354 \\
\hline Targeted temperature management, $n(\%)$ & $16(48)$ & $3(30)$ & $13(57)$ & 0.161 \\
\hline Use of mechanical compression system, $n(\%)$ & $1(3)$ & $0(0)$ & $1(4)$ & 0.697 \\
\hline E-CPR, $n(\%)$ & $1(3)$ & $0(0)$ & $1(4)$ & 0.503 \\
\hline VV-ECMO-before CA, $n(\%)$ & $8(24)$ & $3(30)$ & $5(22)$ & 0.611 \\
\hline \multicolumn{5}{|l|}{ ICU characteristics } \\
\hline \multicolumn{5}{|l|}{ Severity of illness } \\
\hline SAPS II (pts.) median (IQR) & $44(37-52)$ & $40.5(35-53)$ & $47(38-52)$ & 0.472 \\
\hline SOFA-before CA (pts.) median (IQR) & $12(10-15)$ & $9(6-12)$ & $13(12-15.5)$ & 0.038 \\
\hline SOFA-after CA (pts.) median (IQR) & $15(12-16)$ & $12(9-13)$ & $16(13.5-17)$ & 0.01 \\
\hline SOFA-24 h after CA (pts.) median (IQR) & $14(10-17)$ & $8(7-13)$ & $16(13.5-17)$ & 0.002 \\
\hline \multicolumn{5}{|l|}{ Lab values-post CA median (IQR) } \\
\hline Lactate-highest after CA, mmol/1 & $4.6(3.1-8.3)$ & $3.4(1.4-4.5)$ & $6.1(4.2-12.7)$ & 0.016 \\
\hline $\mathrm{pH}$-lowest after CA & $7.2(7.12-7.3)$ & $7.4(7.18-7.46)$ & $7.2(7.06-7.25)$ & 0.034 \\
\hline Horowitz Index median (IQR) & $114(80-154)$ & $93(65-174)$ & $97(67-140)$ & 0.685 \\
\hline \multicolumn{5}{|l|}{ Procedures/complications during ICU } \\
\hline Mechanical ventilation, $n(\%)$ & $32(97)$ & $10(100)$ & $22(96)$ & 0.503 \\
\hline Extracorporeal membrane oxygenation, $n(\%)$ & $17(53)$ & $6(60)$ & $11(48)$ & 0.52 \\
\hline Vasopressor therapy, $n(\%)$ & $32(97)$ & $9(90)$ & $23(100)$ & 0.503 \\
\hline Renal replacement therapy, $n(\%)$ & $22(67)$ & $5(50)$ & $17(74)$ & 0.181 \\
\hline Coronary angiography-post CA, $n(\%)$ & $1(3)$ & $0(0)$ & $1(4)$ & 0.891 \\
\hline Hypoxic liver injury, $n(\%)$ & $7(21)$ & $2(20)$ & $5(22)$ & 0.911 \\
\hline Cholestasis-Bilirubin $>2 \mathrm{mg} / \mathrm{dl}, n(\%)$ & $15(45)$ & $1(10)$ & $14(61)$ & 0.007 \\
\hline
\end{tabular}

Abbreviations: CA, cardiac arrest; E-CPR, extracorporeal cardiopulmonary resuscitation; ICU, intensive care unit; IQR, inter quartile range; n, number; min, minute; pts., points; ROSC, return of spontaneous circulation; SAPS, Simplified Acute Physiology Score; SOFA, Sequential Organ Failure Assessment; VF, ventricular fibrillation; VT, ventricular tachycardia; MAP, mean arterial pressure.

Before cardiac arrest, the SAPS II and SOFA score were median 44 (37-52) and 12 (10-15) points, respectively. During the ICU stay $97 \%(n=32)$ patients with ICU-CA received MV. Prior to ICU-CA $27 \%(n=9)$ received NIV/HFNC and $70 \%(n=23)$ were mechanically ventilated. The median $p /$ F-Ratio before CA was 114 (80-154). Overall, $53 \%(n=17)$ had support via ECMO. Ten (30\%) patients had veno-venous ECMO before ICU-CA, and $8(24 \%)$ patients were on ECMO at the time of ICU-CA. One patient received E-CPR due to refractory cardiac arrest. Peri-arrest ECMO was established in $15 \%(n=5)$ due to persistent hypoxemia; all were configured as veno-venous ECMO. A total of $97 \%$ $(n=32)$ of patients received vasopressor therapy during the ICU stay, and $82 \%(n=27)$ were on vasopressors before CA (for detailed hemodynamic characteristics, see Supplementary Table S3). Of interest, echocardiography assessment revealed that three (9\%) patients 
presented cor pulmonale. A total of $24 \%(n=8)$ received RRT before CA, and RRT was newly initiated in $42 \%(n=14)$ after CA. Liver dysfunction was observed frequently: $21 \%$ $(n=7)$ suffered from hypoxic liver injury and $45 \%(n=15)$ from cholestasis.

\subsection{Survival, Functional Outcome and Risk Factors for ICU-CA}

Of the 183 included patients, $42 \%(n=76)$ did not survive the ICU stay. Patients with ICU-CA had a significant higher ICU mortality $(61 \%, n=20)$ as compared to other patients $(37 \%, n=56)$. Of patients with ICU-CA, 24\% $(n=8)$ died within ICU-CA $24 \mathrm{~h}$ after CA. At ICU discharge, $30 \%(n=10)$ of patients with ICU-CA presented with favorable neurological outcome (CPC $1 / 2)$, and $70 \%(n=23)$ with unfavorable (CPC 3/4 or death). Multivariable logistic regression analysis revealed that the most pertinent factors associated with the occurrence of ICU-CA were the presence of ARDS (OR 4.268, 95\% CI (1.211-15.036); $p=0.024)$ and high SAPS II (OR 1.031, 95\% CI (0.997-1.065); $p=0.077)$ (see Supplementary Table S4).

\subsection{Factors Associated with Unfavorable Outcome in Patients with ICU-CA}

Detailed characteristics on ICU-CA with favorable and unfavorable outcome are shown in Table 2 and Supplementary Table S2. Cardiac arrest characteristics were comparable between both groups. A longer total resuscitation time (median 4 vs. 2 min) and a higher rate of cardiac re-arrest $(30 \%$ vs. $0 \%, p=0.049)$ was observed in patients with unfavorable outcome. Lactate (6.1 vs. $3.4 \mathrm{mmol} / \mathrm{L})$ was higher and pH levels (7.2 vs. 7.4) lower after CA in patients with unfavorable outcome (both $p<0.05$ ). The SOFA score before and after ICU-CA was significantly higher in patients with unfavorable outcome. Interventions in place before ICU-CA were well balanced between both groups. Vasopressor therapy was in place in $96 \%$ with unfavorable outcome, as compared to $50 \%$ with favorable outcome $(p=0.002)$. ARDS management, including prone positioning, neuromuscular blockage, corticosteroids and inhaled vasodilatory treatment, was comparable in both groups. Complications during ICU stay were comparable between both groups, and the occurrence of cholestasis was significantly higher in patients with ICU-CA and unfavorable outcome (61\% vs. $10 \%)$.

\section{Discussion}

We investigated the occurrence, characteristics, and outcome as well as risk factors for ICU-CA in critically ill patients with COVID-19. We found that ICU-CA occurred in $18 \%$ of critically ill patients with COVID-19 and was related to more advanced stages of ARDS and severity of illness. To our knowledge, this is the most comprehensive study focusing on factors for occurrence of ICU-CA in patients with COVID-19. Furthermore, this is the first study showing detailed post-ICU-CA characteristics in patients with COVID-19.

The reported incidence of ICU-CA in the literature varies greatly, ranging from $4-$ $78 / 1000$ ICU admissions $[14,15,27]$. However, the incidence declined in past years, probably an expression of advances in the management and treatment of critically ill patients [14]. The highest incidence rates were reported in patients with underlying malignant conditions within a comprehensive cancer center [28]. Mainly, the large variation in incidence is explained by the setting and the cohort studied. Two recent studies in a mixed ICU cohort showed an incidence of 22-23/1000 ICU admissions [17,29]. To our knowledge, only one previous study focused on the occurrence and incidence of cardiac arrest in critically ill patients with COVID-19 treated in the intensive care unit [11]. The study by Hayek and colleagues proposed an incidence of about 80/1000 ICU admissions, whereas we observed an incidence of 180/1000 ICU admissions in the present study. This large difference can potentially be the consequence of different factors. In direct comparison, the median SOFA score on admission was considerably higher in our cohort. Almost three-fourths of patients were mechanically ventilated in our study, which is comparable to the study by Hayek and colleagues [11]. However, only $4 \%$ were treated by ECMO as compared to $28 \%$ in our cohort, which reflects a considerably higher severity of illness. This would be in line 
with our finding that the severity of ARDS is the strongest risk factor for the occurrence of ICU-CA accompanied by the high incidence observed. However, whether this finding is unique in patients with COVID-19 has to be further elucidated. Earlier studies in the setting of ICU-CA did not focus on patients with respiratory insufficiency or ARDS and were mainly conducted in mixed ICU settings. Furthermore, our hospital acts as a referral center specialized in the care of critically ill patients with ARDS. Therefore, we are treating patients who probably have a more severe course of disease and our findings may not be transferable to other hospitals in different settings.

Critically ill patients with COVID-19 mainly suffer from respiratory insufficiency and many patients require mechanical ventilation. Patients with a need for oxygen support are at high risk for rapidly worsening and the development of respiratory failure. Of interest, the deterioration of $\mathrm{SpO}_{2}$ in combination with higher early warning scores have recently been described as predictors for worsening in patients with COVID-19 [30,31]. Therefore, close monitoring and early transfer to a more staffed and monitored setting seems reasonable. However, we strictly followed a protocol for early ICU admission of deteriorating patients with COVID-19 in our institution. We observed a high rate of nonshockable rhythm (91\%), mainly owing to a non-cardiac cause, which is in line with earlier reports of cardiac arrest in COVID-19 [6,10,11,32]. We also observed a high rate of severe ARDS in our cohort, highlighted by the fact that $24 \%$ of patients had an VV-ECMO in place at the time of ICU-CA. The observed resuscitation times in our cohort were mainly short and sustained ROSC was achieved in $94 \%$ of patients. The resuscitation times were slightly longer as compared to an earlier study in the mixed ICU, which may be explained by the need for personal protective equipment and the potential delay in the initiation of CPR. However, compared to other studies on COVID-19, we observed quite low resuscitations times [11]. To date, reported outcomes after IHCA/ICU-CA in patients with COVID-19 are worse, ranging from $88-100 \%$, and have led to discussions about futility and limitation of care $[8,10-12,32]$. Although we observed high mortality in our cohort, it was substantially lower than previously reported. We observed mainly similar cardiac arrest characteristics, but different factors can contribute to better outcome. Firstly, all patients suffered from CA in the ICU. Due to higher nurse/doctor staffing and continuous monitoring, this could explain faster response times and lower times to ROSC. Secondly, some reports derived from regions with a high excessive patient load during the pandemic, possibly contributing to factors associated with worse outcome.

Organ dysfunction and organ failure after CA is frequently observed [16,33-37]. The high morbidity and mortality after CA were shown to be mainly triggered by post-CA shock and brain injury $[16,38]$. The effects of pre-existing organ dysfunction and organ support are less clear. In our cohort, more than $90 \%$ of patients had invasive or non-invasive respiratory support at the time of ICU-CA. One large study observed that mechanical ventilation at the time of CA is associated with noticeably decreased survival [39]. However, we did not observe differences regarding survival in patients with ICU-CA. About $80 \%$ of patients had vasopressor support in place at the time of ICU-CA; we observed an association with an unfavorable outcome. This is in line with two previous studies which also found an association with the pre-arrest use of vasopressors with unfavorable outcome [40,41]. About one-fourth of the patients received RRT prior to ICU-CA and RRT was newly initiated in $42 \%$ of patients after ICU-CA. We did not observe an association with unfavorable outcome as compared to earlier studies in OHCA patients [34]. Of interest, we observed that $21 \%$ suffered from hypoxic liver injury and $45 \%$ from cholestasis, which is in line with earlier reports in critically ill patients with COVID-19 [42]. Although hypoxic liver injury was shown to be associated with unfavorable outcome in ICU-CA, we did not observe this in the present study $[17,33]$. However, cholestasis was significantly associated with unfavorable outcome in our cohort. This was previously shown in critically ill patients, but not in patients after CA [43].

We observed a significantly higher severity of illness in patients suffering from ICU-CA compared to patients without ICU-CA. Of interest, these differences were already evident 
on admission, represented by SOFA and SAPS II, and we found that a high SAPS II score was associated with the occurrence of ICU-CA. Although the median time from admission to ICU-CA was 6 days, about one-third of the cohort suffered ICU-CA within $24 \mathrm{~h}$ of ICU admission, highlighting this quite vulnerable patient group. This is also comparable to earlier studies on ICU-CA in mixed ICUs [17]. In our cohort, we observed that severity of illness (SOFA) before and after CA was significantly associated with unfavorable outcome. To our knowledge, only the APACHE III score was evaluated for outcome prediction in ICU-CA before and showed moderate predictive performance [44]. However, SOFA score can be easily and quickly assessed. Future studies have to clarify if there is a value of SOFA score in outcome prediction compared to other scoring systems used after ICU-CA.

This study has several limitations. Firstly, we present data deriving from a single center very experienced in the management of CA and post-CA care as well as ARDS and COVID-19. Thus, our results may not be transferrable to other settings. Secondly, we cannot entirely exclude the possibility that changes in general management and advances in critical care of patients with COVID-19 had influence on the occurrence and outcome of ICU-CA. Thirdly, the data were collected retrospectively from a prospectively documented PDMS filled by trained ICU staff. Fourthly, residual confounding is a matter of concern and cannot be entirely excluded. Fifthly, our cohort of patients with ICU-CA was small. Future studies have to clarify and confirm our findings in a larger setting.

\section{Conclusions}

In conclusion, this is the first study in critically ill patients with COVID-19 focusing on the post-CA course of ICU-CA. We found that $18 \%$ of critically ill patients suffered from ICU-CA with a corresponding incidence of 180/1000 ICU admissions. The occurrence of ICU-CA was strongly associated with higher stages of ARDS and severity of illness on admission. Although patients with ICU-CA suffered from high mortality, cardiopulmonary resuscitation in this selected patient cohort is not futile.

Supplementary Materials: The following are available online at https:/ /www.mdpi.com/article/10 $.3390 / \mathrm{jcm} 10102195 / \mathrm{s} 1$, Table S1 - pre-existing comorbidities of patients stratified according to ICU cardiac arrest (ICU-CA) and no ICU cardiac arrest (No ICU-CA); Table S2—-detailed characteristics of respiratory support and ICU therapies in patients with ICU-CA stratified according favorable and unfavorable outcome; Table S3-hemodynamic characteristics of in patients with ICU-CA stratified according favorable and unfavorable outcome; Table S4-logistic regression model for factors associated with occurrence of ICU-CA.

Author Contributions: K.R., G.S., D.J. and S.K. participated in the study conception and design. K.R., G.S., D.J., O.B., G.d.H., C.B., D.F., B.S., D.W. (Dominic Wichmann), D.W. (Dirk Westermann), A.N. were involved in the acquisition of data. K.R., D.J. and S.K. contributed to the analysis and interpretation of data. K.R. drafted the manuscript. S.K. and D.J. were involved in the critical revision of the manuscript for important intellectual content. S.K., G.S. and D.J. participated in the supervision. All authors have read and agreed to the published version of the manuscript.

Funding: This research received no external funding.

Institutional Review Board Statement: The Ethics Committee of the Hamburg Chamber of Physicians was informed about the study (No.: WF-WF-60/21). The study was approved by the local clinical institutional review board and complied with the Declaration of Helsinki.

Informed Consent Statement: The requirement for informed patient consent was waived due to the use of anonymized data from routine clinical care only.

Data Availability Statement: Data sharing is not applicable to this article.

Conflicts of Interest: K.R., G.S., O.B., G.d.H., C.B., B.S., D.W. (Dirk Westermann) and D.J. do not report any conflicts of interest related to this article. S.K. received research support by Ambu, E.T.View Ltd., Fisher and Paykel, Pfizer and Xenios, lecture honoraria from ArjoHuntleigh, Astellas, Astra, Basilea, Bard, Baxter, Biotest, CSL Behring, CytoSorbents, Fresenius, Gilead, MSD, Orion, Pfizer, Philips, Sedana, Sorin, Xenios and Zoll, and consultant honorarium from AMOMED, Astellas, 
Baxter, Bayer, Fresenius, Gilead, MSD, Pfizer and Xenios. A.N. received research funds, lecture honoraria and travel reimbursement within the last 5 years from CytoSorbents Europe, Biotest AG and ThermoFisher Scientific. D.F. reports lecture honoraria within the last 5 years from Xenios AG. D.W. (Dominic Wichmann) received lecture and consultant honorarium from Gilead, MSD, Pfizer, Shionogi and reports no other potential conflict of interest relevant to this article.

\section{References}

1. Guan, W.J.; Ni, Z.Y.; Hu, Y.; Liang, W.H.; Ou, C.Q.; He, J.X.; Liu, L.; Shan, H.; Lei, C.L.; Hui, D.S.C.; et al. Clinical Characteristics of Coronavirus Disease 2019 in China. N. Engl. J. Med. 2020, 382, 1708-1720. [CrossRef] [PubMed]

2. WHO. WHO_World Map—COVID-19. Available online: https:/ / covid19. who.int/ (accessed on 26 March 2021).

3. Roedl, K.; Jarczak, D.; Thasler, L.; Bachmann, M.; Schulte, F.; Bein, B.; Weber, C.F.; Schäfer, U.; Veit, C.; Hauber, H.P.; et al. Mechanical ventilation and mortality among 223 critically ill patients with coronavirus disease 2019: A multicentric study in Germany. Aust. Crit. Care Off. J. Confed. Aust. Crit. Care Nurses 2020. [CrossRef]

4. Baldi, E.; Sechi, G.M.; Mare, C.; Canevari, F.; Brancaglione, A.; Primi, R.; Klersy, C.; Palo, A.; Contri, E.; Ronchi, V.; et al. Out-of-Hospital Cardiac Arrest during the Covid-19 Outbreak in Italy. N. Engl. J. Med. 2020. [CrossRef] [PubMed]

5. Marijon, E.; Karam, N.; Jost, D.; Perrot, D.; Frattini, B.; Derkenne, C.; Sharifzadehgan, A.; Waldmann, V.; Beganton, F.; Narayanan, K.; et al. Out-of-hospital cardiac arrest during the COVID-19 pandemic in Paris, France: A population-based, observational study. Lancet Public Health 2020. [CrossRef]

6. Sultanian, P.; Lundgren, P.; Strömsöe, A.; Aune, S.; Bergström, G.; Hagberg, E.; Hollenberg, J.; Lindqvist, J.; Djärv, T.; Castelheim, A.; et al. Cardiac arrest in COVID-19: Characteristics and outcomes of in- and out-of-hospital cardiac arrest. A report from the Swedish Registry for Cardiopulmonary Resuscitation. Eur. Heart J. 2021. [CrossRef] [PubMed]

7. Roedl, K.; Söffker, G.; Fischer, D.; Müller, J.; Westermann, D.; Issleib, M.; Kluge, S.; Jarczak, D. Effects of COVID-19 on in-hospital cardiac arrest: Incidence, causes, and outcome-A retrospective cohort study. Scand. J. TraumaResusc. Emerg. Med. 2021, 29, 30. [CrossRef] [PubMed]

8. Shao, F.; Xu, S.; Ma, X.; Xu, Z.; Lyu, J.; Ng, M.; Cui, H.; Yu, C.; Zhang, Q.; Sun, P.; et al. In-hospital cardiac arrest outcomes among patients with COVID-19 pneumonia in Wuhan, China. Resuscitation 2020, 151, 18-23. [CrossRef]

9. Sung, C.-W.; Lu, T.-C.; Fang, C.-C.; Huang, C.-H.; Chen, W.-J.; Chen, S.-C.; Tsai, C.-L. Impact of COVID-19 pandemic on emergency department services acuity and possible collateral damage. Resuscitation 2020, 153, 185-186. [CrossRef]

10. Sheth, V.; Chishti, I.; Rothman, A.; Redlener, M.; Liang, J.; Pan, D.; Mathew, J. Outcomes of In-Hospital Cardiac Arrest in Patients with COVID-19 in New York City. Resuscitation 2020, 155, 3-5. [CrossRef]

11. Hayek, S.S.; Brenner, S.K.; Azam, T.U.; Shadid, H.R.; Anderson, E.; Berlin, H.; Pan, M.; Meloche, C.; Feroz, R.; O'Hayer, P.; et al. In-hospital cardiac arrest in critically ill patients with covid-19: Multicenter cohort study. BMJ 2020, 371, m3513. [CrossRef]

12. Shah, P.; Smith, H.; Olarewaju, A.; Jani, Y.; Cobb, A.; Owens, J.; Moore, J.; Chenna, A.; Hess, D. Is Cardiopulmonary Resuscitation Futile in Coronavirus Disease 2019 Patients Experiencing In-Hospital Cardiac Arrest? Crit. Care Med. 2020. [CrossRef]

13. Mitchell, O.J.L.; Yuriditsky, E.; Johnson, N.J.; Doran, O.; Buckler, D.G.; Neefe, S.; Seethala, R.R.; Motov, S.; Moskowitz, A.; Lee, J.; et al. In-Hospital Cardiac Arrest in Patients with Coronavirus 2019. Resuscitation 2021. [CrossRef]

14. Efendijev, I.; Nurmi, J.; Castrén, M.; Skrifvars, M.B. Incidence and outcome from adult cardiac arrest occurring in the intensive care unit: A systematic review of the literature. Resuscitation 2014, 85, 472-479. [CrossRef]

15. Armstrong, R.A.; Kane, C.; Oglesby, F.; Barnard, K.; Soar, J.; Thomas, M. The incidence of cardiac arrest in the intensive care unit: A systematic review and meta-analysis. J. Intensive Care Soc. 2019, 20, 144-154. [CrossRef]

16. Lemiale, V.; Dumas, F.; Mongardon, N.; Giovanetti, O.; Charpentier, J.; Chiche, J.D.; Carli, P.; Mira, J.P.; Nolan, J.; Cariou, A. Intensive care unit mortality after cardiac arrest: The relative contribution of shock and brain injury in a large cohort. Intensive Care Med. 2013, 39, 1972-1980. [CrossRef]

17. Roedl, K.; Jarczak, D.; Blohm, R.; Winterland, S.; Müller, J.; Fuhrmann, V.; Westermann, D.; Söffker, G.; Kluge, S. Epidemiology of intensive care unit cardiac arrest: Characteristics, comorbidities, and post-cardiac arrest organ failure-A prospective observational study. Resuscitation 2020, 156, 92-98. [CrossRef]

18. Nolan, J.P.; Soar, J.; Cariou, A.; Cronberg, T.; Moulaert, V.R.M.; Deakin, C.D.; Bottiger, B.W.; Friberg, H.; Sunde, K.; Sandroni, C. European Resuscitation Council and European Society of Intensive Care Medicine Guidelines for Post-resuscitation Care 2015: Section 5 of the European Resuscitation Council Guidelines for Resuscitation 2015. Resuscitation 2015, 95, 202-222. [CrossRef]

19. Storm, C. Biomarkers after resuscitation: Relevance in daily clinical practice for prognosis estimation and definition of therapeutic goals. Med. Klin. Intensiomed. Notf. 2019, 114, 313-318. [CrossRef]

20. Nolan, J.P.; Berg, R.A.; Andersen, L.W.; Bhanji, F.; Chan, P.S.; Donnino, M.W.; Lim, S.H.; Ma, M.H.; Nadkarni, V.M.; Starks, M.A.; et al. Cardiac Arrest and Cardiopulmonary Resuscitation Outcome Reports: Update of the Utstein Resuscitation Registry Template for In-Hospital Cardiac Arrest: A Consensus Report From a Task Force of the International Liaison Committee on Resuscitation (American Heart Association, European Resuscitation Council, Australian and New Zealand Council on Resuscitation, Heart and Stroke Foundation of Canada, InterAmerican Heart Foundation, Resuscitation Council of Southern Africa, Resuscitation Council of Asia). Resuscitation 2019, 144, 166-177. [CrossRef] 
21. Fuhrmann, V.; Jäger, B.; Zubkova, A.; Drolz, A. Hypoxic hepatitis—Epidemiology, pathophysiology and clinical management. Wien. Klin. Wochenschr. 2010, 122, 129-139. [CrossRef]

22. Ranieri, V.M.; Rubenfeld, G.D.; Thompson, B.T.; Ferguson, N.D.; Caldwell, E.; Fan, E.; Camporota, L.; Slutsky, A.S. Acute respiratory distress syndrome: The Berlin Definition. JAMA 2012, 307, 2526-2533. [CrossRef]

23. Kluge, S.; Janssens, U.; Welte, T.; Weber-Carstens, S.; Marx, G.; Karagiannidis, C. German recommendations for critically ill patients with COVID-19. Med. Klin. Intensiomed. Notf. 2020, 1-4. [CrossRef] [PubMed]

24. Vincent, J.L.; Moreno, R.; Takala, J.; Willatts, S.; De Mendonça, A.; Bruining, H.; Reinhart, C.K.; Suter, P.M.; Thijs, L.G. The SOFA (Sepsis-related Organ Failure Assessment) score to describe organ dysfunction/failure. On behalf of the Working Group on Sepsis-Related Problems of the European Society of Intensive Care Medicine. Intensive Care Med. 1996, 22, 707-710. [CrossRef] [PubMed]

25. Le Gall, J.R.; Lemeshow, S.; Saulnier, F. A new Simplified Acute Physiology Score (SAPS II) based on a European/North American multicenter study. JAMA 1993, 270, 2957-2963. [CrossRef] [PubMed]

26. Charlson, M.E.; Pompei, P.; Ales, K.L.; MacKenzie, C.R. A new method of classifying prognostic comorbidity in longitudinal studies: Development and validation. J. Chronic Dis. 1987, 40, 373-383. [CrossRef]

27. Efendijev, I.; Raj, R.; Reinikainen, M.; Hoppu, S.; Skrifvars, M.B. Temporal trends in cardiac arrest incidence and outcome in Finnish intensive care units from 2003 to 2013. Intensive Care Med. 2014, 40, 1853-1861. [CrossRef] [PubMed]

28. Wallace, S.; Ewer, M.S.; Price, K.J.; Feeley, T.W. Outcome and cost implications of cardiopulmonary resuscitation in the medical intensive care unit of a comprehensive cancer center. Supportive Care Cancer Off. J. Multinatl. Assoc. Supportive Care Cancer 2002, 10, 425-429. [CrossRef] [PubMed]

29. Leloup, M.; Briatte, I.; Langlois, A.; Cariou, A.; Lesieur, O. Unexpected cardiac arrests occurring inside the ICU: Outcomes of a French prospective multicenter study. Intensive Care Med. 2020. [CrossRef]

30. Pimentel, M.A.F.; Redfern, O.C.; Hatch, R.; Young, J.D.; Tarassenko, L.; Watkinson, P.J. Trajectories of vital signs in patients with COVID-19. Resuscitation 2020, 156, 99-106. [CrossRef]

31. Covino, M.; Sandroni, C.; Santoro, M.; Sabia, L.; Simeoni, B.; Bocci, M.G.; Ojetti, V.; Candelli, M.; Antonelli, M.; Gasbarrini, A.; et al. Predicting intensive care unit admission and death for COVID-19 patients in the emergency department using early warning scores. Resuscitation 2020, 156, 84-91. [CrossRef]

32. Thapa, S.B.; Kakar, T.S.; Mayer, C.; Khanal, D. Clinical Outcomes of In-Hospital Cardiac Arrest in COVID-19. JAMA Intern. Med. 2020. [CrossRef]

33. Roedl, K.; Spiel, A.O.; Nurnberger, A.; Horvatits, T.; Drolz, A.; Hubner, P.; Warenits, A.M.; Sterz, F.; Herkner, H.; Fuhrmann, V. Hypoxic liver injury after in- and out-of-hospital cardiac arrest: Risk factors and neurological outcome. Resuscitation 2019, 137, 175-182. [CrossRef]

34. Geri, G.; Guillemet, L.; Dumas, F.; Charpentier, J.; Antona, M.; Lemiale, V.; Bougouin, W.; Lamhaut, L.; Mira, J.P.; Vinsonneau, C.; et al. Acute kidney injury after out-of-hospital cardiac arrest: Risk factors and prognosis in a large cohort. Intensive Care Med. 2015, 41, 1273-1280. [CrossRef]

35. Laurent, I.; Monchi, M.; Chiche, J.D.; Joly, L.M.; Spaulding, C.; Bourgeois, B.; Cariou, A.; Rozenberg, A.; Carli, P.; Weber, S.; et al. Reversible myocardial dysfunction in survivors of out-of-hospital cardiac arrest. J. Am. Coll. Cardiol. 2002, 40, $2110-2116$. [CrossRef]

36. Roberts, B.W.; Kilgannon, J.H.; Chansky, M.E.; Mittal, N.; Wooden, J.; Parrillo, J.E.; Trzeciak, S. Multiple organ dysfunction after return of spontaneous circulation in postcardiac arrest syndrome. Crit Care Med. 2013, 41, 1492-1501. [CrossRef]

37. Roedl, K.; Wallmuller, C.; Drolz, A.; Horvatits, T.; Rutter, K.; Spiel, A.; Ortbauer, J.; Stratil, P.; Hubner, P.; Weiser, C.; et al. Outcome of in- and out-of-hospital cardiac arrest survivors with liver cirrhosis. Ann. Intensive Care 2017, 7, 103. [CrossRef]

38. Neumar, R.W.; Nolan, J.P.; Adrie, C.; Aibiki, M.; Berg, R.A.; Böttiger, B.W.; Callaway, C.; Clark, R.S.B.; Geocadin, R.G.; Jauch, E.C.; et al. Post-cardiac arrest syndrome: Epidemiology, pathophysiology, treatment, and prognostication. A consensus statement from the International Liaison Committee on Resuscitation (American Heart Association, Australian and New Zealand Council on Resuscitation, European Resuscitation Council, Heart and Stroke Foundation of Canada, InterAmerican Heart Foundation, Resuscitation Council of Asia, and the Resuscitation Council of Southern Africa); the American Heart Association Emergency Cardiovascular Care Committee; the Council on Cardiovascular Surgery and Anesthesia; the Council on Cardiopulmonary, Perioperative, and Critical Care; the Council on Clinical Cardiology; and the Stroke Council. Circulation 2008, 118, $2452-2483$. [CrossRef]

39. Al-Alwan, A.; Ehlenbach, W.J.; Menon, P.R.; Young, M.P.; Stapleton, R.D. Cardiopulmonary resuscitation among mechanically ventilated patients. Intensive Care Med. 2014, 40, 556-563. [CrossRef]

40. Grigoriyan, A.; Vazquez, R.; Palvinskaya, T.; Bindelglass, G.; Rishi, A.; Amoateng-Adjepong, Y.; Manthous, C.A. Outcomes of cardiopulmonary resuscitation for patients on vasopressors or inotropes: A pilot study. J. Crit. Care 2009, 24, 415-418. [CrossRef]

41. Tian, J.; Kaufman, D.A.; Zarich, S.; Chan, P.S.; Ong, P.; Amoateng-Adjepong, Y.; Manthous, C.A. Outcomes of critically ill patients who received cardiopulmonary resuscitation. Am. J. Respir. Crit. Care Med. 2010, 182, 501-506. [CrossRef]

42. Roedl, K.; Jarczak, D.; Drolz, A.; Wichmann, D.; Boenisch, O.; de Heer, G.; Burdelski, C.; Frings, D.; Sensen, B.; Nierhaus, A.; et al. Severe liver dysfunction complicating course of COVID-19 in the critically ill: Multifactorial cause or direct viral effect? Ann. Intensive Care 2021, 11, 44. [CrossRef] [PubMed] 
43. Kramer, L.; Jordan, B.; Druml, W.; Bauer, P.; Metnitz, P.G. Incidence and prognosis of early hepatic dysfunction in critically ill patients-A prospective multicenter study. Crit Care Med. 2007, 35, 1099-1104. [CrossRef] [PubMed]

44. Skrifvars, M.B.; Varghese, B.; Parr, M.J. Survival and outcome prediction using the Apache III and the out-of-hospital cardiac arrest (OHCA) score in patients treated in the intensive care unit (ICU) following out-of-hospital, in-hospital or ICU cardiac arrest. Resuscitation 2012, 83, 728-733. [CrossRef] [PubMed] 